\title{
Characterization of the Particulate Methane Monooxygenase Metal Centers in Multiple Redox States by X-ray Absorption Spectroscopy
}

\author{
Raquel L. Lieberman ${ }^{\dagger} \&$, Kalyan C. Kondapalli ${ }^{\ddagger} \&$, Deepak B. Shrestha ${ }^{\dagger}$, Amanda S. \\ Hakemian ${ }^{\dagger}$, Stephen M. Smith ${ }^{\dagger}$, Joshua Telser ${ }^{\dagger} \S$, Jane Kuzelkall, Rajeev Gupta \\ Borovik $\uparrow$, Stephen J. Lippard ll, Brian M. Hoffman ${ }^{\dagger}$, Amy C. Rosenzweig ${ }^{\star}, \dagger$, and Timothy L. \\ Stemmler ${ }^{*}, \ddagger$ \\ Departments of Biochemistry, Molecular Biology, and Cell Biology and of Chemistry, Northwestern \\ University, Evanston, Illinois 60208, Department of Biological, Chemical and Physical Sciences, \\ Roosevelt University, Chicago, Illinois 60605, Department of Chemistry, Massachusetts Institute of \\ Technology, Cambridge, Massachusetts 02139, Department of Chemistry, University of Kansas, \\ Lawrence, Kansas 66045, and Department of Biochemistry and Molecular Biology, Wayne State \\ University, School of Medicine, Detroit, Michigan 48201
}

\section{Abstract}

The integral membrane enzyme particulate methane monooxygenase (pMMO) converts methane, the most inert hydrocarbon, to methanol under ambient conditions. The $2.8-\AA$ resolution pMMO crystal structure revealed three metal sites: a mononuclear copper center, a dinuclear copper center, and a nonphysiological mononuclear zinc center. Although not found in the crystal structure, solution samples of pMMO also contain iron. We have used X-ray absorption spectroscopy to analyze the oxidation states and coordination environments of the pMMO metal centers in as-isolated $\left(\mathrm{pMMO}_{\mathrm{iso}}\right)$, chemically reduced $\left(\mathrm{pMMO}_{\text {red }}\right)$, and chemically oxidized $\left(\mathrm{pMMO}_{\mathrm{ox}}\right)$ samples. X-ray absorption near-edge spectra (XANES) indicate that $\mathrm{pMMO}_{\text {iso }}$ contains both $\mathrm{CuI}$ and CuII and that the pMMO $\mathrm{Cu}$ centers can undergo redox chemistry. Extended X-ray absorption fine structure (EXAFS) analysis reveals a $\mathrm{Cu}-\mathrm{Cu}$ interaction in all redox forms of the enzyme. $\mathrm{The} \mathrm{Cu}-\mathrm{Cu}$ distance increases from 2.51 to $2.65 \AA$ upon reduction, concomitant with an increase in the average $\mathrm{Cu}-\mathrm{O} / \mathrm{N}$ bond lengths. Appropriate $\mathrm{Cu}_{2}$ model complexes were used to refine and validate the EXAFS fitting protocols for $\mathrm{pMMO}_{\text {iso }}$. Analysis of Fe EXAFS data combined with electron paramagnetic resonance (EPR) spectra indicates that $\mathrm{Fe}$, present as $\mathrm{Fe}^{\mathrm{III}}$, is consistent with heme impurities. These findings are complementary to the crystallographic data and provide new insight into the oxidation states and possible electronic structures of the pMMO Cu ions.

\footnotetext{
*To whom correspondence should be addressed. amyr@ northwestern.edu (A.C.R.), tstemmle@ med.wayne.edu (T.L.S.).

†Northwestern University.

$\&$ The authors contributed equally to this work.

‡Wayne State University, School of Medicine.

\$Roosevelt University.

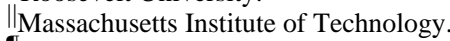

IUUniversity of Kansas.
}

Supporting Information Available: Strategies for calibrating fitting parameters and choosing best-fit simulations, comparison of Fourier transforms of $\mathrm{Cu}$ metal vs pMMO red Cu EXAFS (Figure S1), and Q-band EPR spectrum of $\mathrm{pMMO}_{\text {iso }}$ (Figure S2). This material is available free of charge via the Internet at http://pubs.acs.org. 


\section{Introduction}

In the first step of the metabolic pathway of methanotrophic bacteria, ${ }^{1}$ methane monooxygenase (MMO) enzymes convert methane to methanol at a catalytic metal center. ${ }^{2}$, ${ }^{3}$ As the only known enzymes that can activate the inert $(104 \mathrm{kcal} / \mathrm{mol}) \mathrm{C}-\mathrm{H}$ bond in methane, MMOs and the related ammonia monooxygenase ${ }^{4}$ are relevant to the development of new industrial catalysts. All strains of methanotrophs express the membrane-bound form, particulate methane monooxygenase (pMMO), ${ }^{2}$ and several can also express a soluble form $(\mathrm{sMMO})^{3}$ under conditions of $\mathrm{Cu}$ starvation. ${ }^{5,6}$ Detailed knowledge of the atomic and electronic structures of the MMO catalytic metal centers is crucial to understanding the mechanism of methane oxidation. In sMMO, $\mathrm{C}-\mathrm{H}$ activation occurs at a carboxylate-bridged $\mathrm{Fe}_{2}$ center ${ }^{7}$ and several reactive intermediates have been detected and characterized. ${ }^{3,8} \mathrm{By}$ contrast, knowledge of the pMMO active site structure and mechanism is limited.

The crystal structure of pMMO from Methylococcus capsulatus (Bath), recently determined to $2.8-\AA$ resolution, reveals an $\sim 300 \mathrm{kDa}$ trimer composed of three copies each of the pMMO polypeptides pmoA ( $\beta$ subunit), pmoB ( $\alpha$ subunit), and pmoC ( $\gamma$ subunit). ${ }^{9}$ Each $\alpha \beta \gamma$ protomer contains three discrete metal centers. Mononuclear and dinuclear copper centers reside $\sim 25$ and $\sim 10 \AA$ above the surface of the membrane, respectively, in the soluble regions of pmoB. The mononuclear $\mathrm{Cu}$ center is coordinated by His 48 and His 72 from pmoB with nearly linear geometry (Figure 1A). The dinuclear $\mathrm{Cu}$ center is ligated by the amino terminus and side chain of His 33, His 137, and His 139 from pmoB (Figure 1B). The third site, occupied by a $\mathrm{Zn}$ ion in the crystal, is located $\sim 13 \AA$ below the surface of the membrane and is coordinated by Asp 156, His 160, and His 173 from pmoC and Glu 195 from pmoA (Figure 1C). The presence of $\mathrm{Zn}$ at this site is a crystallization artifact, and the physiological metal ion is not known. The identity of the catalytic center remains a major question. Although $2.8-\AA \AA$ resolution is excellent for a membrane protein structure, the coordinate error precludes obtaining metrical parameters and accurate descriptions of coordination geometry. Exogenous ligands, likely present in both $\mathrm{Cu}$ centers, are not observed. In addition, the crystal structure does not provide any information regarding the oxidation states of the $\mathrm{Cu}$ centers.

X-ray absorption spectroscopy (XAS) can supply some of this information as well as provide support and verification of the crystallographic model. Prior to solving the crystal structure, we initiated XAS studies of purified M. capsulatus (Bath) pMMO containing 2-3 Cu ions and $0.4-1 \mathrm{Fe}$ ions per $100 \mathrm{kDa} .{ }^{10}$ The X-ray absorption near-edge spectrum (XANES) exhibited a shoulder at $8984 \mathrm{eV}$, indicative of $\mathrm{Cu}^{\mathrm{I}}$ in as-isolated pMMO. Extended X-ray absorption fine structure (EXAFS) data revealed a $\mathrm{Cu}-$ metal interaction at $2.57 \AA$, which we fit as a $\mathrm{Cu}-\mathrm{Cu}$ interaction, although the possibility of a $\mathrm{Cu}-\mathrm{Fe}$ interaction could not be excluded at that time. On the basis of these XAS data and electron paramagnetic resonance (EPR) spectroscopic studies, we proposed that the pMMO Cu centers exist in a mononuclear center and as a Cucontaining cluster, ${ }^{2,10}$ the details of which were elucidated by the crystal structure. ${ }^{9}$ In this report, we present a comprehensive XAS analysis of purified pMMO. We employed four synthetic $\mathrm{Cu}_{2}$ model complexes to obtain more accurate EXAFS fitting protocols for the asisolated protein. In addition, we expand upon the general understanding of pMMO by analyzing the different metal centers after treatment with dithionite and hydrogen peroxide. Our results support the crystallographic data and provide accurate metrical parameters as well as new insight into the oxidation states of the pMMO metal ions. We also address the nature of the $\mathrm{Fe}$ found in pMMO samples purified by our laboratory ${ }^{10}$ and others. ${ }^{11,12}$ 


\section{Experimental Section pMMO Sample Preparation}

M. capsulatus (Bath) cultures were fermented and membranes were isolated as described previously. ${ }^{10}$ As-isolated $\left(\mathrm{pMMO}_{\mathrm{iso}}\right)$ and dithionite-reduced $\left(\mathrm{pMMO}_{\mathrm{red}}\right)$ samples were prepared using a method also described previously. ${ }^{10}$ This purification protocol differs slightly from that used to generate samples for crystallography. ${ }^{9}$ Samples contained $2-4 \mathrm{Cu}$ ions per $100 \mathrm{kDa}$, as determined by inductively coupled plasma atomic emission spectroscopy (ICPAES) using a Thermo Jarrell Ash Atomscan model 25 sequential ICP spectrometer. In an attempt to oxidize pMMO ( $\mathrm{pMMO}_{\mathrm{ox}}$ ), a solution of $3 \% \mathrm{H}_{2} \mathrm{O}_{2}$ was added dropwise to a stirring suspension of crude membranes to a final concentration of 0.02 or $0.05 \%(\mathrm{v} / \mathrm{v}) \mathrm{H}_{2} \mathrm{O}_{2}$. The solution was allowed to stir at room temperature for 3 or $5 \mathrm{~h}$, respectively. The samples turned from translucent brown to opaque gray. Each sample was diluted 1:1 with a $50 \mathrm{mg} / \mathrm{mL} n$ dodecyl- $\beta$-D-maltoside (12 M, Anatrace) solution in water and centrifuged at $20800 \mathrm{~g}$ for 10 min to remove unsolubilized material, and crude pMMO was purified as described previously.

10 This procedure was used because previous attempts to oxidize purified pMMO with ferricyanide $^{10}$ and other oxidants ${ }^{9}$ gave no increase in the EPR signal intensity. All XAS samples were diluted in $50 \mathrm{mM}$ Hepes, $\mathrm{pH} 7.5,0.25 \mathrm{M} \mathrm{NaCl}$, and $0.05 \% 12 \mathrm{M}$ and $50 \%$ glycerol and concentrated to 1 and $10 \mathrm{mM} \mathrm{Cu}$, corresponding to 0.2 and $2 \mathrm{mM} \mathrm{Fe}$. The high-Cuconcentration samples were used when measuring protein Fe XAS. Samples were loaded into Kapton-wrapped Lucite cells (pMMO $_{\text {red }}$ samples were also loaded into a Coy anaerobic chamber), flash frozen in liquid $\mathrm{N}_{2}$, and stored at $-80{ }^{\circ} \mathrm{C}$ prior to data collection. All XAS measurements were performed on multiple, independently prepared samples to ensure reproducibility of our results.

\section{$\mathrm{Cu}_{2}$ Model Complexes}

Structurally characterized mixed-valent dinuclear $\mathrm{Cu}$ model compounds were used to calibrate the metal-ligand EXAFS interaction in $\mathrm{pMMO}_{\text {iso. }}$. Samples of [tris $\left\{\left(N^{\prime}\right.\right.$-tert-butylureaylato $)$ $N$-ethyl $\}$ aminatocopper(II) $]_{2} \mathrm{BF}_{4}$ (M1) and $[N$-tert-butylurealylato- $\{2$-(dimethylamino) ethyl $\}$ aminatocopper(II) $]_{2} \mathrm{BF}_{4}(\mathbf{M 2})$, which are blue, were prepared according to a previously published protocol. ${ }^{13}$ Similarly, purple samples of $\left[\mathrm{Cu}_{2}(m\right.$-xylylene- diaminebis(Kemp's triacid imide $)(\mu$-OTf $\left.)(\mathrm{THF})_{2}\right]$ (M3) and $\left[\mathrm{Cu}_{2}(m\right.$-xylylenediaminebis(Kemp's triacid imide $)$ ) $\left.\left(\mu-\mathrm{O}_{2} \mathrm{CCF}_{3}\right)(\mathrm{THF})_{2}\right]$ (M4) were prepared according to published protocols. ${ }^{14}$ Samples were stored as solids, transported to the synchrotron under strict anaerobic conditions, and immediately placed in an anaerobic chamber. In the anaerobic chamber, all four samples were diluted with boron nitride (Aldrich), packed into Al transmission cells wrapped in Kapton tape, flash frozen, and stored in liquid $\mathrm{N}_{2}$ until data collection.

\section{XAS Data Collection and Analysis}

XAS data were collected at Stanford Synchrotron Radiation Laboratory (SSRL) beamlines 7-3 and 10-2 and at National Synchrotron Light Source (NSLS) beamline X9-b. Both SSRL beamlines were equipped with $\mathrm{Si}(220)$ double-crystal monochromators detuned $50 \%$ for harmonic rejection, whereas NSLS beamline X9-b was equipped with a $\mathrm{Si}(111)$ monochromator equipped with a harmonic rejection mirror. Samples were maintained at $10 \mathrm{~K}$ using Oxford Instruments continuous-flow liquid-He cryostats at SSRL and at $24 \mathrm{~K}$ using a He Displex Cryostat at NSLS. Protein fluorescence excitation spectra were collected using 30element Ge solid-state array detectors at SSRL and a 13-element Ge solid-state detector at NSLS. Mn and Ni filters ( $0.6 \mathrm{mM}$ in width) were placed between the cryostat and detector to filter scattering fluorescence not associated with the $\mathrm{Fe}$ and $\mathrm{Cu}$ signals, respectively. Transmission data were recorded on model compounds using ionization detectors, filled with $\mathrm{N}_{2}$ gas, placed before and after the cryostat. XAS spectra were measured using 5-eV steps in the preedge regions $(6900-7094 \mathrm{eV}$ for $\mathrm{Fe}$ and $8750-8960 \mathrm{eV}$ for $\mathrm{Cu}$ ), $0.25-\mathrm{eV}$ steps in the 
edge regions (7095-7135 eV for $\mathrm{Fe}$ and $8986-9050 \mathrm{eV}$ for $\mathrm{Cu}$ ), and $0.05-\AA^{-1}$ increments in the EXAFS region (to $k=13.5 \AA^{-1}$ for $\mathrm{Fe}$ and $\mathrm{Cu}$ ), integrating from 1 to $20 \mathrm{~s}$ in a $k^{3}$-weighted manner for a total scan length of approximately $40 \mathrm{~min}$. X-ray energies were calibrated by collecting $\mathrm{Fe}$ or $\mathrm{Cu}$ foil absorption spectra simultaneously with protein and model data and assigning the first inflection point as $7111 \mathrm{eV}$ for the $\mathrm{Fe}$ foil and $8980.3 \mathrm{eV}$ for the $\mathrm{Cu}$ foil. Each fluorescence channel of each scan was examined for spectral anomalies prior to averaging, and spectra were closely monitored for photoreduction. SSRL data represent the average of 6-7 scans, while NSLS data represent the average of 9-10 scans.

XAS data were processed using the Macintosh OS X version of the EXAFSPAK program suite $^{15}$ integrated with the Feff v7 software ${ }^{16}$ for theoretical model generation. Data reduction utilized a Gaussian function in the preedge region and a three-region cubic spline through the EXAFS region. Data were converted to $k$ space using $E_{0}$ values of $7130 \mathrm{eV}$ for Fe and 9000 $\mathrm{eV}$ for $\mathrm{Cu}$. The $k^{3}$-weighted EXAFS was truncated at 1.0 and $13.35 \AA^{-1}$ (for $\mathrm{Fe}$ ) and 1.0 and $12.85 \AA^{-1}$ (for $\mathrm{Cu}$ ) for filtering purposes and Fourier-transformed. These spectral $k$ ranges correspond to spectral resolutions of ca. $0.13 \AA$ for both the $\mathrm{Fe}$-and $\mathrm{Cu}$-ligand interactions; therefore, only independent scattering environments outside $0.13 \AA$ were considered resolvable in the EXAFS fitting analysis. ${ }^{17}$

The fitting analyses of our EXAFS data were performed on both Fourier-filtered and raw/ unfiltered data. Each method gave equivalent structural results. Model and protein EXAFS data were fit using both single- and multiple-scattering amplitude and phase functions calculated using Feff v7. Single-scattering Feff v7 models were calculated for C, O, S, and Cu coordination to simulate $\mathrm{Cu}$-ligand environments and for $\mathrm{C}, \mathrm{O}, \mathrm{S}$, and $\mathrm{Fe}$ coordination to simulate Fe-ligand environments. Multiple-scattering Feff v7 models were generated for $\mathrm{Fe}-$ and $\mathrm{Cu}$-imidazole and $\mathrm{Fe}$-porphyrin interactions utilizing crystallographic coordinates for $\mathrm{Zn}$ and $\mathrm{Mn}$-imidazole and $\mathrm{Fe}$-porphyrin systems. ${ }^{18,19}$ Appropriate scale factors $(\mathrm{Sc})$ and $E_{0}$ values used when fitting $\mathrm{Cu}$ and $\mathrm{Fe}$ data were calibrated by fitting crystallographically characterized $\mathrm{Cu}$ (italics in Table 1) and $\mathrm{Fe}^{20}$ model compounds. Strategies for calibrating Sc and $E_{0}$ are outlined in the Supporting Information. Criteria for judging best-fit EXAFS simulations, utilizing the lowest mean-square deviation between data and fit corrected for the number of degrees of freedom $\left(F^{\prime}\right),{ }^{21}$ are outlined in the Supporting Information.

\section{EPR Spectroscopy}

EPR spectra were recorded on a modified Varian E-4 spectrometer equipped with a $\mathrm{N}_{2}$-flow cryostat. The acquisition temperature was $120 \mathrm{~K}$, as determined by a thermocouple placed in the sample area. An aqueous solution of copper ethylenediaminetetraacetic acid (1.0 $\mathrm{mM})$ was used as the standard, and EPR spectra of pMMO samples were recorded under conditions (9.20GHz microwave frequency, 6-mW microwave power, 5-G field modulation amplitude, 125ms time constant, and 4-min scan time) identical to those for the standard. The spectra were corrected for background by subtraction of a spectrum for buffer recorded under identical conditions. Double integration of background-corrected spectra was done digitally using LabCalc software. The same field integration range was used for all samples, and the spectra were baseline-corrected (linear) after the first digital integration. Q-band (35-GHz) EPR spectra were recorded at $2 \mathrm{~K}$ on a modified Varian E-9 spectrometer, described elsewhere. ${ }^{22}$ Under the experimental conditions employed, the spectra appear as the absorption envelope, rather than as the first-derivative presentation, enhancing the detection of weak, broad signals. 


\section{Results}

\section{XANES Analysis}

In compounds M1-M4 (Figure 1D,E), an unpaired electron is fully delocalized between the two Cu ions. All four model XANES spectra show preedge features at $8980 \mathrm{eV}$ (areas of 1.4, 1.1, 1.6, and 1.8 for M1-M4, respectively), characteristic of the $1 \mathrm{~s} \rightarrow 3 \mathrm{~d}$ transition for centrosymmetric $\mathrm{Cu}^{\mathrm{II}}$ (Figure 2 inset), and features at $8984 \mathrm{eV}$, attributable to the $\mathrm{Cu}^{\mathrm{I}} 1 \mathrm{~s} \rightarrow$ $4 \mathrm{p}$ transition (Figure $2 \mathrm{~A}$ ). ${ }^{23}$ The XANES spectrum for $\mathrm{pMMO}_{\text {red }}$ closely resembles spectra reported for three- to four-coordinate $\mathrm{Cu}^{\mathrm{I}}$ compounds, based on the intensity of the $1 \mathrm{~s} \rightarrow 4 \mathrm{p}$ transition, the overall edge structure, and the lack of any discernible $1 \mathrm{~s} \rightarrow 3 \mathrm{~d}$ feature (Figure 2 , inset). ${ }^{23}$ The XANES spectrum for $\mathrm{pMMO}_{\text {iso }}$ (Figure $2 \mathrm{~B}$ ) has a reduced, but observable, $1 \mathrm{~s}$ $\rightarrow 4 \mathrm{p}$ transition and a weak $1 \mathrm{~s} \rightarrow 3 \mathrm{~d}$ feature similar to those seen in the spectra for M2-M4, consistent with $\mathrm{Cu}$ in this sample being a mixture of $\mathrm{Cu}^{\mathrm{I}}$ and $\mathrm{Cu}^{\mathrm{II}}$. The $1 \mathrm{~s} \rightarrow 4 \mathrm{p}$ spectral feature is further diminished, although present, in the $\mathrm{pMMO}_{\text {ox }}$ spectrum (Figure 2B), and this spectrum also displays an apparent $1 \mathrm{~s} \rightarrow 3 \mathrm{~d}$ signal. These data would be consistent with incomplete $\mathrm{Cu}$ oxidation or possibly a loss of $\mathrm{Cu}$-ligand symmetry for metal in the cupric state. ${ }^{24} \mathrm{EPR}$ quantitation indicated that both $\mathrm{pMMO}_{\text {iso }}$ and $\mathrm{pMMO}_{\text {ox }}$ contain $\sim 40 \%$ EPR-active $\mathrm{Cu}$, but oxidation need not be accompanied by an increase in the EPR signal intensity if an EPRsilent $\mathrm{Cu}_{2}$ site is oxidized to a strongly coupled $\mathrm{Cu}_{2}{ }_{2}$ site. In addition, it is possible that the persisting 8984-eV feature in the $\mathrm{pMMO}_{\text {ox }}$ sample results from instantaneous photoreduction upon exposure to $\mathrm{X}$-rays. The intensity of this feature is equivalent in subsequent scans for each sample. Although $\mathrm{Cu}{ }^{\mathrm{III}}$ has been invoked in some models of the pMMO Cu centers, ${ }^{25} \mathrm{a}$ shift of the $1 \mathrm{~s} \rightarrow 3 \mathrm{~d}$ feature suggestive of $\mathrm{Cu}^{\mathrm{III}} 26$ is not observed in the XANES spectra.

$\mathrm{Cu}$ XANES spectra were extended past the energy of $9659 \mathrm{eV}$ to identify the extent of $\mathrm{Zn}$ fluorescence in our data and, hence, to directly measure the population in the mononuclear $\mathrm{Zn}$ site observed in the crystal structure. ${ }^{9}$ The $\mathrm{Zn}$ fluorescence edge was less than $3 \%$ of the $\mathrm{Cu}$ edge in each sample that we tested. These data therefore indicate that the mononuclear $\mathrm{Zn}$ site seen in the crystal structure was not populated by a $\mathrm{Zn}$ ion. It is therefore possible that this mononuclear site could be populated by $\mathrm{Cu}$ or other additional metals.

\section{Model Compound EXAFS}

Crystallographically characterized mixed-valence dinuclear $\mathrm{Cu}$ model complexes M1-M4 were used to refine protocols for fitting $\mathrm{pMMO}_{\text {iso }}$ EXAFS. The $\mathrm{Cu}$ ions in these compounds are separated by 2.38-2.43 $\AA$ and are coordinated by either mixed N and O (M1 and M2) or all O (M3 and M4) ligands. Fourier transforms of the EXAFS spectra for M1-M4 show intense features at phase-shifted bond lengths of less than $3 \AA$ (Figure 3). Spectral features at $1.6 \AA$ are consistent with average $\mathrm{Cu}-\mathrm{O} / \mathrm{N}$ coordination environments at approximately $2.0 \AA$. Features at $2.0 \AA$ are consistent with the $\mathrm{Cu}-\mathrm{Cu}$ interactions at approximately $2.4 \AA$. In addition, all four models exhibit long-range scattering (>3.0 $\mathrm{A}$ ) consistent with the semirigid environments imposed by the synthetic ligand scaffolds.

EXAFS fits for M1-M4 helped us refine our strategies for fitting authentic $\mathrm{Cu}-\mathrm{Cu}$ interactions in mixed-valent $\mathrm{Cu}^{\mathrm{I}} / \mathrm{Cu}^{\mathrm{II}}$ metalloproteins. In addition, these fits helped us define the correct scale factor $(\mathrm{Sc})$ and energy shift function $\left(E_{0}\right)$ needed to calibrate Feff v7 generated theoretical models for fitting empirical data. To obtain Sc and $E_{0}$ values, model EXAFS data were initially fit using the average $\mathrm{Cu}$-ligand bond length and coordination parameters obtained from the crystal structures (listed in italics in Table 1). The best overall fit for each model type is listed in bold. In the M1-M4 fits, we utilized data over a $k$ range of 1-13.1 $\AA^{-1}$.

Using our simulation strategy outlined in the Supporting Information, we simulated the $\mathrm{Cu}$ EXAFS for all four dinuclear model compounds (Figure 3). In each case, the best single- 
environment fits consisted of $\mathrm{Cu}-\mathrm{O} / \mathrm{N}$ fits that were fairly disordered, as denoted by high Debye-Waller factors (Table 1, $x .1$ fits, where $x$ is the model number identifier). The inclusion of an additional $\mathrm{Cu}-\mathrm{O} / \mathrm{N}$ shell was justified in each model, based on decreasing $F^{\prime}$ values with acceptable Debye-Waller factors for all environments (Table 1, $x .2$ fits). Including a $\mathrm{Cu}-\mathrm{Cu}$ interaction significantly improved the simulations for all models, as shown by the dramatic decrease in $F^{\prime}$ values (Table 1, x.3 fits). The addition of a third $\mathrm{Cu}-\mathrm{O} / \mathrm{N}$ ligand system was only justified for M3. The $\mathrm{Cu}-\mathrm{Cu}$ interactions match well $( \pm 0.02 \AA)$ to the average parameters determined from the published crystal structures,${ }^{13,14}$ but fits to the $\mathrm{Cu}-\mathrm{O} / \mathrm{N}$ nearest-neighbor interactions were less successful (between \pm 0.02 and 0.06). In fits to M1, M2, and M4, all ligand environment parameters match crystallographic values reasonably well ( $\pm 0.08 \AA$ of the crystal value).

\section{pMMO Cu EXAFS}

Fourier transforms of the $\mathrm{Cu}$ EXAFS data for $\mathrm{pMMO}_{\text {iso }}, \mathrm{pMMO}_{\text {red }}$, and $\mathrm{pMMO}_{\mathrm{ox}}$ show two scattering interactions, corresponding to ligands at approximately 2 and $2.5 \AA$ (Figure 4). In addition, long-range ligand interactions $(>3 \AA$ ) are evident. The camelback beat pattern in the EXAFS at $k=4 \AA^{-1}$, which is characteristic of imidazole ligation, is directly detectable in the $\mathrm{pMMO}_{\text {iso }}$ sample but less pronounced or absent in the $\mathrm{pMMO}_{\mathrm{ox}}$ and $\mathrm{pMMO}_{\text {red }}$ samples. ${ }^{27}$,

${ }^{28}$ For all pMMO samples, the EXAFS data were best fit using a mixture of $\mathrm{Cu}-\mathrm{O} / \mathrm{N}$ and $\mathrm{Cu}-$ $\mathrm{Cu}$ ligand environments. Fits with a single set of $\mathrm{O} / \mathrm{N}$ ligands gave dramatically better $F^{\prime}$ values than fits with a single $\mathrm{Cu}-\mathrm{S}$ or $\mathrm{Cu}-\mathrm{Cu}$ environment, as previously observed. ${ }^{10}$ The average single-environment fits gave $\mathrm{Cu}-\mathrm{O} / \mathrm{N}$ bond lengths that are lower in $\mathrm{pMMO}_{\mathrm{ox}}(1.95 \AA)$ and $\mathrm{pMMO}_{\text {iso }}(1.97 \AA)$ than in $\mathrm{pMMO}_{\text {red }}(2.11 \AA$ ) (Table 2, fits 5.1, 6.1, and 7.1, respectively). All fits were improved with the addition of a second $\mathrm{Cu}-\mathrm{O} / \mathrm{N}$ ligand environment. For $\mathrm{pMMO}_{\text {red }}$ and $\mathrm{pMMO}_{\mathrm{ox}}$, the bond distances are distributed between 1.93 and $2.11 \AA$, whereas in $\mathrm{pMMO}_{\text {iso }}$, the second $\mathrm{Cu}-\mathrm{O} / \mathrm{N}$ environment in $\mathrm{pMMO}_{\text {iso }}$ is best fit with a longer bond length of $2.22 \AA$, suggesting a redistribution or rearrangement of $\mathrm{O} / \mathrm{N}$-based ligands concurrent with changes in the $\mathrm{Cu}$ redox states.

There was a significant improvement in the fits to all samples when scattering interactions at $>2.5 \AA$ were included. Inclusion of a $\mathrm{Cu}-\mathrm{Cu}$ interaction in the pMMO EXAFS simulations was justified for all samples (Table 2). The $\mathrm{Cu}-\mathrm{Cu}$ bond length of $2.65 \AA$ for $\mathrm{pMMO}_{\text {red }}$ is substantially longer than the 2.51-Å length observed for $\mathrm{pMMO}_{\text {iso }}$ and $\mathrm{pMMO}_{\mathrm{ox}}$. In our initial EXAFS analysis of $\mathrm{pMMO}_{\text {iso }}$, the $\mathrm{Cu}-$ metal interaction was best fit with a 2.57 - $\AA$ distance, 10 but this distance has been adjusted by $0.06 \AA$ as a result of better calibrated fitting parameters. The $2.65-\AA \mathrm{Cu}-\mathrm{Cu}$ interaction in the reduced sample is different from the $2.58-\AA$ distance expected for $\mathrm{Cu}$-metal, suggesting that the integrity of the metal centers is maintained upon reduction (Figure S1 in the Supporting Information). In all samples, we were able to fit the data with long-range $\mathrm{C}$ scattering using single-scattering models, and in the case of $\mathrm{pMMO}_{\mathrm{iso}}$ and $\mathrm{pMMO}_{\mathrm{ox}}$, these fits are reminiscent of fitting imidazole interactions. ${ }^{28}$ In the case of $\mathrm{pMMO}_{\text {iso }}$ and $\mathrm{pMMO}$ ox , the inclusion of $\mathrm{C}$ scattering at $>3 \AA$ and a second long-range environment at $>3.8 \AA$ was justified. Although the $\mathrm{pMMO}_{\text {red }}$ data could also be fit with both interactions, only the inclusion of the $>3-\AA$ fit was justified, based on the improvement in $F^{\prime}$. We were not able to fit long-range $(>3-\AA)$ scattering with a $\mathrm{Cu} \cdots \mathrm{Cu}$ interaction, eliminating the possibility that our sample contains any appreciable $\mathrm{Cu}$ metal. Attempts were made to fit the data using a multiple-scattering $\mathrm{Cu}$-imidazole model, and the data could be fit with reasonable success (Table 2, “*”.N fits), but in no case were these fits an improvement over the single-scattering model fits. The inability to simulate the pMMO data with multiplescattering imidazole models may result from the fact that there are multiple $\mathrm{Cu}$-imidazole interactions at each of the pMMO Cu centers (Figure 1) and their EXAFS most likely interfere destructively. 


\section{PMMO Fe XANES/EXAFS}

To address the identity of the interacting metal in the $2.51-\AA \mathrm{Cu}-$ metal interaction, we collected

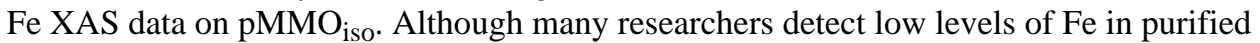
pMMO samples, ${ }^{10-12}$ a physiological role for Fe has not been experimentally determined. The $\mathrm{pMMO}_{\text {iso }}$ Fe XANES spectrum (Figure 5) closely resembles the spectrum observed for ferric ammonium sulfate, indicating that $\mathrm{Fe}$ copurified with $\mathrm{pMMO}_{\text {iso }}$ is predominantly $\mathrm{Fe}^{\mathrm{III}}$ and that the ligand environment most likely contains $\mathrm{O} / \mathrm{N}$-based ligands. The first inflection point for $\mathrm{pMMO}_{\text {iso }}$ is $7124.3 \pm 0.6 \mathrm{eV}$. Using a linear equation obtained from the first inflection point of the XANES spectrum for ferrous ammonium sulfate $(7120.9 \pm 0.2 \mathrm{eV})$ and for ferric ammonium sulfate $(7125.5 \pm 0.5 \mathrm{eV})$ as our Fe redox state limits, the $\mathrm{pMMO}_{\text {iso }} \mathrm{Fe}$ edge is estimated to be $75 \pm 19 \%$ ferric. Interestingly, the XANES spectrum resembles that of metmyoglobin. ${ }^{19}$

The Fourier transform of the Fe EXAFS is also reminiscent of heme proteins ${ }^{19}$ and suggests a partially symmetric Fe nearest-neighbor environment with bond lengths $<2.5 \AA$ and longrange scattering at $>2.5 \AA$ (Figure 6). EXAFS fitting results indicate a mixed $\mathrm{Fe}-\mathrm{O} / \mathrm{N}$ nearestneighbor environment of four $\mathrm{Fe}-\mathrm{O} / \mathrm{N}$ interactions at $1.97 \AA$ and a second $\mathrm{Fe}-\mathrm{O} / \mathrm{N}$ environment at $2.12 \AA$. In addition, we observe that the long-range scattering can only be fit with C-based ligands. Importantly, there is no Fe-metal scattering in the range of 2.5-2.65 $\AA$, establishing that the $\mathrm{Cu}$-metal scattering observed in the $\mathrm{Cu}$ EXAFS is not due to a $\mathrm{Cu}-\mathrm{Fe}$ interaction. The best overall EXAFS fit (Table 3, fit 8.6) was obtained by simulating the long-range scattering with four separate $\mathrm{Fe}-\mathrm{C}$ interactions that were all simulated with single-scattering Feff v7 models. The bond lengths resemble the principal ligand interactions seen in $\mathrm{Fe}$-porphyrin systems (Fe-N interactions at $1.95 \AA, \mathrm{Fe}-\mathrm{C}$ interactions at $3.01 \AA$, $\mathrm{Fe}-\mathrm{C}$ interactions at 3.37 $\AA$, and $\mathrm{Fe}-\mathrm{C}$ interactions at $4.26 \AA$ ). ${ }^{29}$ Attempts to fit the $\mathrm{Fe}$ data with $\mathrm{Fe}-$ porphyrin or $\mathrm{Fe}-$ imidazole models were moderately successful, but these fits were worse than the singlescattering fits. Nevertheless, these results strongly suggest that the $\mathrm{Fe}$ in the $\mathrm{pMMO}_{\text {iso }}$ samples is due to heme Fe, which was detected previously in the optical spectrum of purified pMMO. ${ }^{10} \mathrm{In}$ addition, Q-band EPR spectra acquired at $2 \mathrm{~K}$ confirm the presence of high-spin heme $\left(g_{\perp}=6.00 ; g_{\|}\right.$at 2.00 is not observable because of overlap by the much more intense $\mathrm{Cu}^{\mathrm{II}}$ signal from $\mathrm{pMMO}_{\text {iso }}$ (Figure $\mathrm{S} 2$ in the Supporting Information)). Because heme was not observed in the crystal structure, ${ }^{9}$ the Fe likely derives from a cytochrome contaminant.

\section{Discussion}

Although the crystal structure of pMMO has been valuable in locating the pMMO metal centers within the polypeptide fold, the metrical and geometrical parameters are not well defined at 2.8 - $\AA$ resolution, exogenous ligands are not visible, and the oxidation states of the metal ions cannot be determined. In biology, mononuclear and dinuclear $\mathrm{Cu}$ sites can each perform hydroxylation and electron-transfer functions, of which both must occur in the conversion of methane to methanol. The functions of the individual $\mathrm{Cu}$ centers therefore cannot be inferred from the crystal structure and the active site of pMMO remains unknown. On the basis of reported metal ion compositions, ${ }^{2}$ the physiological metal ion at the crystallographic $\mathrm{Zn}$ site is likely $\mathrm{Cu}$ or Fe. XAS is a complementary technique to study coordination environment and redox changes in pMMO. In this study, we have determined ligand bond distances to $\mathrm{Cu}$ by using appropriate models for improved EXAFS fitting, we have established the identity of the interacting metal in the dinuclear $\mathrm{Cu}$-containing cluster, characterized the $\mathrm{Fe}$ in $\mathrm{pMMO}$ solution samples, and gained information regarding the oxidation state(s) of the $\mathrm{Cu}$ ions.

Numerous groups have used XAS to study systems containing multinuclear $\mathrm{Cu}$ clusters with short $\mathrm{Cu}-\mathrm{Cu}$ distances, and standard fitting protocols are well documented. ${ }^{30-32}$ We refined these strategies for mixed-valent $\mathrm{Cu}^{\mathrm{I}} / \mathrm{Cu}^{\mathrm{II}}$ systems using model compounds $\mathrm{M1}-\mathbf{M} 4$, which resemble pMMO in average nearest-neighbor coordination environments and average 
oxidation state. The utility of our approach is demonstrated by the excellent agreement between the overall best-fit parameters and the crystal structures (Table 1). The pMMO Cu EXAFS data fit with our refined protocol corroborate the presence of both $\mathrm{Cu}$ centers in the crystal structure (Figure 1A,B). The average Cu EXAFS data indicate nonsymmetric Cu nearestneighbor environments constructed of $\mathrm{Cu}-\mathrm{O} / \mathrm{N}$ and $\mathrm{Cu}-$ metal interactions. In addition, longrange interactions show characteristic features of imidazole scattering, consistent with the prevalence of coordinated histidines. The presence of multiple independent $\mathrm{Cu}$ centers from the crystal structure populated with different $\mathrm{Cu}$ stoichiometries explains why singleenvironment fits were disordered, and the coordination number of 0.5 for the $\mathrm{Cu}-\mathrm{Cu}$ interaction is consistent with only a fraction of the total $\mathrm{Cu}$ existing in a $\mathrm{Cu}-\mathrm{Cu}$ cluster. In the crystal structure, 2 out of $3 \mathrm{Cu}$ ions are in the cluster, whereas the coordination number of 0.25 suggests that only a portion of the bound $\mathrm{Cu}$ is in the cluster and this cluster is partially disordered. One way to reconcile these findings is if the mononuclear metal binding site, occupied by $\mathrm{Zn}$ in the crystal structure, contains $\mathrm{Cu}$ in the XAS samples. If $\mathrm{Cu}$ is, in fact, occupying this $\mathrm{Zn}$ site in the XAS samples, one would expect an average $\mathrm{Cu}-\mathrm{Cu}$ coordination number for these fits to be less than or at best equal to 0.5 , which, in fact, we see in all samples. The presence of a $\mathrm{Cu}-$ $\mathrm{Cu}$ center, rather than a $\mathrm{Cu}-\mathrm{Fe}$ center, is confirmed by the absence of $\mathrm{Fe}-\mathrm{Cu}$ scattering at $\sim 2.5$ $\AA$ in the Fe EXAFS. The fact that the Fe EXAFS resembles a porphyrin system, combined with the EPR spectrum and the lack of Fe or heme in the crystal structure, suggests that $\mathrm{Fe}$ found in purified $\mathrm{pMMO}^{10-12}$ is not intrinsic to the enzyme but due to impurities.

The Cu EXAFS further suggests that exogenous ligands are probably present because the 2$4 \mathrm{O} / \mathrm{N}$ ligands simulated for each pMMO sample is higher than the two $\mathrm{N}$ ligands coordinated to each $\mathrm{Cu}$ ion in the structure (Figure 1A,B). This notion is supported by the similarity of the pMMO EXAFS to that of the model compounds, which contain four (M1 and M2) or five ligands (M3 and M4). Finally, our data give no indication of $\mathrm{Cu}-\mathrm{S}$ ligation, which is consistent with the absence of cysteine ligands in the crystal structure and suggests that inorganic sulfide, which bridges the nitrous oxide reductase tetranuclear $\mathrm{Cu}_{\mathrm{Z}}$ cluster, ${ }^{33,34}$ is not a likely exogenous ligand.

A comparison of the pMMO XANES to that of the model compounds indicates that $\mathrm{pMMO}_{\text {iso }}$ is a mixture of $\mathrm{Cu}^{\mathrm{I}}$ and $\mathrm{Cu}$, as suggested previously. ${ }^{\mathrm{II}}$ Changes in the XANES upon treatment with dithionite or hydrogen peroxide indicate that the pMMO $\mathrm{Cu}$ centers can undergo redox chemistry. Although the EXAFS data for all three samples were best fit with 2-4 O/N ligands, the average coordination distance increases as the sample is reduced, and the populations of the independent ligand environments redistribute. The relationship of the 2.22 $\AA \mathrm{Cu}-\mathrm{O} / \mathrm{N}$ distance in $\mathrm{pMMO}_{\text {iso }}$ to the oxidation state is not clear. One possibility is that this distance corresponds to a flexible interaction between the amino terminal $\mathrm{N}$ atom of His 33 and the dinuclear center (Figure 1B). The $\mathrm{Cu}-\mathrm{Cu}$ distance of $2.51 \AA$ for $\mathrm{pMMO}_{\text {iso }}$ and $\mathrm{pMMO}_{\mathrm{ox}}$ increases to $2.65 \AA$ for $\mathrm{pMMO}_{\text {red }}$, suggesting that the dinuclear site can be reduced. $\mathrm{The} \mathrm{Cu}-\mathrm{Cu}$ bond distances for the cytochrome $c$ oxidase $\mathrm{Cu}_{\mathrm{A}}$ site increase by $\sim 0.1 \AA$ upon conversion from the mixed-valence $\mathrm{Cu}^{1.5} \mathrm{Cu}^{1.5}$ form to the $\mathrm{Cu}^{\mathrm{I}} \mathrm{Cu}^{\mathrm{I}}$ form. ${ }^{35}$ Similar trends are observed for model complexes as well. ${ }^{36}$ The identical $\mathrm{Cu}-\mathrm{Cu}$ distances obtained for $\mathrm{pMMO}_{\text {iso }}$ and $\mathrm{pMMO}_{\mathrm{ox}}$ suggest that any $\mathrm{H}_{2} \mathrm{O}_{2}$-mediated oxidation does not occur at the dinuclear site.

These data provide new insight into the possible oxidation states of the pMMO Cu ions. Although $\mathrm{Cu}$ in the EXAFS samples could occupy the crystallographic Zn site, as suggested by the coordination number of 0.25 for the $\mathrm{Cu}-\mathrm{Cu}$ interaction (vide supra), no experimental evidence for $\mathrm{Cu}$ in this site is yet available. Therefore, we will primarily consider only mononuclear and dinuclear $\mathrm{Cu}$ sites in the following discussion of possible redox scenarios. According to the XAS data, $\mathrm{pMMO}_{\text {iso }}$ contains both $\mathrm{Cu}^{\mathrm{I}}$ and $\mathrm{Cu}^{\mathrm{II}}$, and the $\mathrm{Cu}-\mathrm{Cu}$ distance is affected by reduction. EPR data indicate the presence of a mononuclear type 2 site, and $\sim 40 \%$ 
of the $\mathrm{pMMO}_{\text {iso }} \mathrm{Cu}$ is EPR-active. One possibility (scenario 1) is that all three $\mathrm{Cu}$ ions in $\mathrm{pMMO}_{\text {iso }}$ are $\mathrm{Cu}^{\mathrm{II}}$. In this case, the type $2 \mathrm{EPR}$ signal would be attributable to the mono-nuclear site, and the dinuclear center must be strongly antiferromagnetically coupled $\mathrm{Cu}^{\mathrm{II}} \mathrm{Cu}^{\mathrm{II}}$ and EPR-silent. Upon reduction, the dinuclear site becomes fully $\mathrm{Cu}^{\mathrm{I}} \mathrm{Cu}^{\mathrm{I}}$, explaining the change in the $\mathrm{Cu}-\mathrm{Cu}$ distance. This scenario is not consistent with the presence of $\mathrm{Cu}^{\mathrm{I}}$ in $\mathrm{pMMO}_{\text {iso }}$, however, unless we invoke $\mathrm{Cu}^{\mathrm{I}}$ in the crystallographic $\mathrm{Zn}$ site or instantaneous photoreduction. Another option (scenario 2) is that the mononuclear site is $\mathrm{Cu}^{\mathrm{II}}$ and the dinuclear site is $\mathrm{Cu}^{\mathrm{I}} \mathrm{Cu}^{\mathrm{I}}$. Again, the type $2 \mathrm{EPR}$ spectrum would be due to the mononuclear site, but the increase in the $\mathrm{Cu}-\mathrm{Cu}$ distance would have to be attributed to an effect other than a redox change because the dinuclear center is already reduced.

A third possibility is that the mononuclear site is $\mathrm{Cu}^{\mathrm{I}}$ and the dinuclear site is mixed-valence $\mathrm{Cu}^{\mathrm{I}} \mathrm{Cu}^{\mathrm{II}}$ (scenario 3). Mixed-valence sites are classified as completely delocalized, partially delocalized, and completely localized. ${ }^{37}$ Because $\mathrm{pMMO}_{\text {iso }}$ does not exhibit spectroscopic features characteristic of fully delocalized $\mathrm{Cu}^{1.5} \mathrm{Cu}^{1.5}$, as observed for model compounds M1-M4 ${ }^{13,14}$ and biological $\mathrm{Cu}_{\mathrm{A}}$ centers, ${ }^{38}$ a Cu$-\mathrm{Cu}^{\mathrm{II}}$ site must be completely localized or trapped valence. The type 2 EPR spectrum could then derive from the dinuclear site, and reduction would result in a loss of the EPR signal intensity as well as an increase in the $\mathrm{Cu}-$ $\mathrm{Cu}$ distance consistent with a reduction from $\mathrm{Cu}^{\mathrm{I}} \mathrm{Cu}^{\mathrm{II}}$ to $\mathrm{Cu}^{\mathrm{I}} \mathrm{Cu}^{\mathrm{I}}$. The extent of delocalization can be very sensitive to the environment, and in some cases, reversible transitions between valence states have been observed. For example, lowering the $\mathrm{pH}$ from 7 to 4 and protonating a coordinated histidine converts a delocalized $\mathrm{Cu}_{\mathrm{A}}$ center to a trapped valence center. ${ }^{39} \mathrm{In}$ another example, halide binding to the hemocyanin $\mathrm{Cu}_{2}$ center modulates the extent of delocalization. ${ }^{40}$ Therefore, if we assume that the pMMO dinuclear site is in a trapped valence state, this scenario is compatible with all of the available data.

The results for $\mathrm{pMMO}_{\mathrm{ox}}$ also need to be considered in the context of the oxidation state scenarios. The amount of EPR-active $\mathrm{Cu}$ did not change upon hydrogen peroxide treatment, suggesting that either oxidation was not successful or oxidation cannot be detected by EPR. It may be that oxidation requires the presence of a substrate. In support of this idea, recent studies by Chan and co-workers suggest that hydrogen peroxide oxidation is effective only in the presence of the suicide substrate acetylene. ${ }^{25}$ Those experiments, however, were conducted using dithionite-treated pMMO membranes rather than as-isolated membranes.

If we assume that oxidation by hydrogen peroxide does occur, as suggested by the XAS data, then scenario 3 could explain the $40 \%$ EPR-active $\mathrm{Cu}$ in both $\mathrm{pMMO}_{\text {iso }}$ and $\mathrm{pMMO}_{\mathrm{ox}}$. Oxidation of the mononuclear $\mathrm{Cu}^{\mathrm{I}}$ to $\mathrm{Cu}^{\mathrm{II}}$ would result in a type 2 signal, and oxidation of $\mathrm{Cu}^{\mathrm{I}} \mathrm{Cu}^{\mathrm{II}}$ to $\mathrm{Cu}^{\mathrm{II}} \mathrm{Cu}^{\mathrm{II}}$ would result in a loss of the EPR type 2 signal, yielding no net change in the intensity. Some effect on the $\mathrm{Cu}-\mathrm{Cu}$ distance would be expected though because both $\mathrm{pMMO}_{\text {iso }}$ and $\mathrm{pMMO}_{\mathrm{ox}}$ have the same $\mathrm{Cu}-\mathrm{Cu}$ distance. Scenario 1 could also be consistent with no change in the EPR signal intensity if the dinuclear $\mathrm{Cu}^{\mathrm{I}} \mathrm{Cu}^{\mathrm{I}}$ site were fully oxidized to a coupled, EPR-silent $\mathrm{Cu}^{\mathrm{II}} \mathrm{Cu}^{\mathrm{II}}$ center. Again, in this case a change in the $\mathrm{Cu}-\mathrm{Cu}$ distance might be expected. Finally, scenario 2, in which all three $\mathrm{Cu}$ ions are $\mathrm{Cu}^{\mathrm{II}}$, would explain the lack of effect of $\mathrm{H}_{2} \mathrm{O}_{2}$, but this still is not consistent with the presence of $\mathrm{Cu}^{\mathrm{I}}$ in the XANES.

\section{Conclusions}

XANES analysis of pMMO indicates the presence of $\mathrm{Cu}^{\mathrm{I}}$ and $\mathrm{Cu}^{\mathrm{II}}$ and demonstrates that the $\mathrm{Cu}$ centers can undergo redox chemistry. EXAFS fitting analysis using appropriate model compounds provides metrical parameters and suggests the presence of exogenous, non-S ligands. Fe EXAFS experiments reveal that pMMO contains a $\mathrm{Cu}-\mathrm{Cu}$, rather than a $\mathrm{Cu}-\mathrm{Fe}$, cluster and strongly suggest that the $\mathrm{Fe}$ is attributable to heme impurities. $\mathrm{The} \mathrm{Cu}-\mathrm{Cu}$ interaction is present in all samples, and the $\mathrm{Cu}-\mathrm{Cu}$ distance increases upon reduction, as do 
the average $\mathrm{Cu}-\mathrm{O} / \mathrm{N}$ bond lengths. Taken together with EPR parameters and quantitation, these data suggest several possible scenarios for the oxidation states of the pMMO Cu ions. Studies to distinguish between these models and to understand the electronic structure of the pMMO $\mathrm{Cu}$ centers are underway.

\section{Supplementary Material}

Refer to Web version on PubMed Central for supplementary material.

\section{Acknowledgments}

This work was supported by Wayne State University (T.L.S.), by NIH Grant DK068139 (T.L.S.), by funds from the David and Lucile Packard Foundation (A.C.R.), by NIH Grant GM070473 (A.C.R.), by NIH Grant GM50781 (A.S.B.), by NIH Grant HL13531 (B.M.H.), and by NIH Grant 32134 (S.J.L.). R.L.L. was supported in part by NIH training Grant GM08382, A.S.H. is the recipient of an NSF Graduate Research Fellowship, and J.K. was supported by NSERC of Canada. The research was carried out at both SSRL and NSLS. SSRL is a national user facility operated by Stanford University on behalf of the U.S. Department of Energy, Office of Basic Energy Sciences. The SSRL Structural Molecular Biology Program is supported by the Department of Energy, Office of Biological and Environmental Research, and by the NIH, National Center for Research Resources, Biomedical Technology Program. NSLS, located at Brookhaven National Laboratory, is supported by the U.S. Department of Energy, Division of Materials Sciences and Division of Chemical Sciences, under Contract DE-AC02-98CH10886. We thank Dr. Pamela Riggs-Gelasco (College of Charleston) for providing the EXAFS data for diferric RNR, which we used to calibrate our Fe-Fe fits.

\section{References}

1. Hanson RS, Hanson TE. Methanotrophic bacteria. Microbiol Rev 1996;60:439-471. [PubMed: 8801441]

2. Lieberman RL, Rosenzweig AC. Biological methane oxidation: regulation, biochemistry, and active site structure of particulate methane monooxygenase. Crit Rev Biochem Mol Biol 2004;39:147-164. [PubMed: 15596549]

3. Merkx M, Kopp DA, Sazinsky MH, Blazyk JL, Müller J, Lippard SJ. Dioxygen activation and methane hydroxylation by soluble methane monooxygenase: a tale of two irons and three proteins. Angew Chem, Int Ed 2001;40:2782-2807.

4. Arp DJ, Sayavedra-Soto LA, Hommes NG. Molecular biology and biochemistry of ammonia oxidation by Nitrosomonas europaea. Arch Microbiol 2002;178:250-255. [PubMed: 12209257]

5. Stanley SH, Prior SD, Leak DJ, Dalton H. Copper stress underlies the fundamental change in intracellular location of methane monooxygenase in methane oxidizing organisms: studies in batch and continuous cultures. Biotechnol Lett 1983;5:487-492.

6. Prior SD, Dalton H. The effect of copper ions on membrane content and methane monooxygenase activity in methanol-grown cells of Methylococcus capsulatus (Bath). J Gen Microbiol 1985;131:155163.

7. Rosenzweig AC, Frederick CA, Lippard SJ, Nordlund P. Crystal structure of a bacterial non-haem iron hydroxylase that catalyses the biological oxidation of methane. Nature 1993;366:537-543. [PubMed: 8255292]

8. Beauvais LG, Lippard SJ. Reactions of the peroxo intermediate of soluble methane monooxygenase hydroxylase with ethers. J Am Chem Soc 2005;127:7370-7378. [PubMed: 15898785]

9. Lieberman RL, Rosenzweig AC. Crystal structure of a membrane-bound metalloenzyme that catalyses the biological oxidation of methane. Nature 2005;434:177-182. [PubMed: 15674245]

10. Lieberman RL, Shrestha DB, Doan PE, Hoffman BM, Stemmler TL, Rosenzweig AC. Purified particulate methane monooxygenase from Methylococcus capsulatus (Bath) is a dimer with both mononuclear copper and a copper-containing cluster. Proc Natl Acad Sci USA 2003;100:3820-3825. [PubMed: 12634423]

11. Choi DW, Kunz RC, Boyd ES, Semrau JD, Antholine WE, Han JI, Zahn JA, Boyd JM, de la Mora AM, DiSpirito AA. The membrane-associated methane monooxygenase pMMO and pMMONADH: quinone oxidoreductase complex from Methylococcus capsulatus Bath. J Bacteriol 2003;185 (19):5755-5764. [PubMed: 13129946] 
12. Basu P, Katterle B, Andersson KK, Dalton H. The membrane-associated form of methane monooxygenase from Methylococcus capsulatus (Bath) is a copper/iron protein. Biochem J 2003;369:417-427. [PubMed: 12379148]

13. Gupta R, Zhang ZH, Powell D, Hendrich MP, Borovik AS. Synthesis and characterization of completely delocalized mixed-valent dicopper complexes. Inorg Chem 2002;41:5100-5106. [PubMed: 12354043]

14. LeCloux DD, Davydov R, Lippard SJ. Mixed-Valence $\mathrm{Cu}(\mathrm{I})-\mathrm{Cu}(\mathrm{II})$ and Heterodimetallic $\mathrm{Cu}(\mathrm{I})-\mathrm{M}$ (II) Bis(carboxylate-bridged) Complexes: Structural, Electrochemical, and Spectroscopic Investigations. Inorg Chem 1998;37(26):6814-6826. [PubMed: 11670817]

15. George, GN.; George, SJ.; Pickering, IJ. EXAFSPAK. 2001. http://www-ssrl.slac.stanford.edu/ george/exafspak/exafs.htm

16. Ankudinov AL, Rehr JJ. Relativistic calculations of spin-dependent X-ray absorption spectra. Phys Rev B 1997;56:R1712-R1715.

17. Lee PA, Citrin PH, Eisenberger P, Kincaid BM. Extended X-ray absorption fine structure-its strengths and limitations as a structural tool. Rev Mod Phys 1981;53(4):769-806.

18. Garrett TPJ, Guss JM, Freeman HC. Hexakis(imidazole)- manganese(II) dichloride tetrahydrate, [Mn $\left.\left(\mathrm{C}_{3} \mathrm{H}_{4} \mathrm{~N}_{2}\right)_{6}\right] \mathrm{Cl}_{2} \cdot 4 \mathrm{H}_{2} \mathrm{O}$. and hexakis(imidazole)zinc(II) dichloride tetrahydrate, $\left[\mathrm{Zn}\left(\mathrm{C}_{3} \mathrm{H}_{4} \mathrm{~N}_{2}\right)_{6}\right] \mathrm{Cl}_{2}$. $4 \mathrm{H}_{2} \mathrm{O}$. Acta Crystallogr 1983;C39:1027-1031.

19. D'Angelo P, Lucarelli D, della Longa S, Benfatto M, Hazemann JL, Feis A, Smulevich G, Ilari A, Bonamore A, Boffi A. Unusual heme iron-lipid acyl chain coordination in Escherichia coli flavohemoglobin. Biophys J 2004;86(6):3882-3892. [PubMed: 15189885]

20. Riggs-Gelasco PJ, Shu L, Chen S, Burdi D, Huynh BH, Que L Jr, Stubbe J. EXAFS characterization of the intermediate $\mathrm{X}$ generated during the assembly of the Escherichia coli ribonucleotide reductase R2 diferric tyrosyl radical cofactor. J Am Chem Soc 1998;120:849-860.

21. Riggs-Gelasco PJ, Stemmler TL, Penner-Hahn JE. XAFS of dinuclear metal sites in proteins and model compounds. Coord Chem Rev 1995;144:245-286.

22. Werst MM, Davoust CE, Hoffman BM. Ligand spin densities in blue copper proteins by Q-band ${ }^{1} \mathrm{H}$ and ${ }^{14} \mathrm{~N}$ ENDOR spectroscopy. J Am Chem Soc 1991;113:1533-1538.

23. Kau LS, Spira-Solomon DJ, Penner-Hahn JE, Hodgson KO, Solomon EI. X-ray absorption edge determination of the oxidation state and coordination number of copper. Application to the type 3 site in Rhus vernicifera laccase and its reaction with oxygen. J Am Chem Soc 1987;109:6433-6442.

24. Fann YC, Ahmed I, Blackburn NJ, Boswell JS, Verkhovskaya ML, Hoffman BM, Wikstrom M. Structure of $\mathrm{CuB}$ in the binuclear heme-copper center of the cytochrome aa3-type quinol oxidase from Bacillus subtilis: an ENDOR and EXAFS study. Biochemistry 1995;34(32):10245-10255. [PubMed: 7640280]

25. Chen KHC, Chen CL, Tseng CF, Yu SSF, Ke SC, Lee JF, Nguyen HT, Elliott SJ, Alben JO, Chan SI. The copper clusters in the particulate methane monooxygenase (pMMO) from Methylococcus capsulatus (Bath). J Chin Chem Soc 2004;51:1081-1098.

26. DuBois JL, Mukherjee P, Stack TDP, Hedman B, Solomon EI, Hodgson KO. A systematic K-edge X-ray absorption spectroscopic study of Cu(III) sites. J Am Chem Soc 2000;122:5775-5787.

27. Loeffen PW, Pettifer RF. An EXAFS calculation using known four-body correlations. Phys Rev Lett 1995;76(4):636-639. [PubMed: 10061509]

28. Stemmler TL, Sossong TM Jr, Goldstein JI, Ash DE, Elgren TE, Kurtz DM Jr. Penner-Hahn JEEXAFS comparison of the dimanganese core structures of manganese catalase arginase and manganesesubstituted ribonucleotide reductase and hemerythrin. Biochemistry 1997;36(32):9847-9858. [PubMed: 9245417]

29. Martinez SE, Huang D, Szczepaniak A, Cramer WA, Smith JL. Crystal structure of chloroplast cytochrome $f$ reveals a novel cytochrome fold and unexpected heme ligation. Structure 1994;2(2): 95-105. [PubMed: 8081747]

30. Zippel F, Ahlers F, Werner R, Haase W, Nolting HF, Krebs B. Structural and functional models for the dinuclear copper active site in catechol oxidases: syntheses, X-ray crystal structures, magnetic and spectral Properties, and X-ray absorption spectroscopic studies in solid state and in solution. Inorg Chem 1996;35(11):3409-3419. [PubMed: 11666546] 
31. Blackburn NJ, Barr ME, Woodruff WH, van der Oost J, de Vries S. Metal-metal bonding in biology: EXAFS evidence for a $2.5 \AA$ copper-copper bond in the $\mathrm{Cu}_{\mathrm{A}}$ center of cytochrome oxidase. Biochemistry 1994;33(34):10401-10407. [PubMed: 8068678]

32. Blackburn NJ, Ralle M, Gomez E, Hill MG, Pastuszyn A, Sanders D, Fee JA. Selenomethioninesubstituted Thermus thermophilus cytochrome ba3: characterization of the $\mathrm{Cu}_{\mathrm{A}}$ site by $\mathrm{Se}$ and $\mathrm{Cu}$ K-EXAFS. Biochemistry 1999;38(22):7075-7084. [PubMed: 10353818]

33. Rasmussen T, Berks BC, Sanders-Loehr J, Dooley DM, Zumft WG, Thomson AJ. The Catalytic Center in Nitrous Oxide Reductase, $\mathrm{Cu}_{\mathrm{Z}}$, Is a Copper Sulfide Cluster. Biochemistry 2000;39:1275312756. [PubMed: 11041839]

34. Brown KR, Djinovic-Carugo K, Haltia T, Cabrito I, Saraste M, Moura JJG, Moura I, Tegoni M, Cambillau C. Revisiting the catalytic $\mathrm{Cu}_{Z}$ cluster of nitrous oxide $\left(\mathrm{N}_{2} \mathrm{O}\right)$ reductase. Evidence of a bridging inorganic sulfur. J Biol Chem 2000;275:41133-41136. [PubMed: 11024061]

35. Blackburn NJ, de Vries S, Barr ME, Houser RP, Tolman WB, Sanders D, Fee JA. X-ray absorption studies on the mixed-valence and fully reduced forms of the soluble $\mathrm{Cu}_{\mathrm{A}}$ domains of cytochrome $c$ oxidase. J Am Chem Soc 1997;119:6135-6143.

36. Kim EJ, Chufán EE, Kamaraj K, Karlin KD. Synthetic models for heme-copper oxidases. Chem Rev 2004;104:1077-1133. [PubMed: 14871150]

37. Robin MB, Day P. Mixed valence chemistry-a survey and classification. Adv Inorg Chem Radiochem 1967;10:247-423.

38. Beinert H. Copper A of cytochrome $c$ oxidase, a novel, long-embattled biological electron-transfer site. Eur J Biochem 1997;245:521-532. [PubMed: 9182986]

39. Hwang HJ, Lu Y. pH-dependent transition between delocalized and trapped valence states of a $\mathrm{Cu}_{\mathrm{A}}$ center and its possible role in proton-coupled electron transfer. Proc Natl Acad Sci USA 2004;101:12842-12847. [PubMed: 15326290]

40. Westmoreland TD, Wilcox DE, Baldwin MJ, Mims WB, Solomon EI. Detailed spectroscopic analysis of half-met hemocyanins: mixed-valent contributions to electronic properties and structure. J Am Chem Soc 1989;111:6106-6123. 
(A)

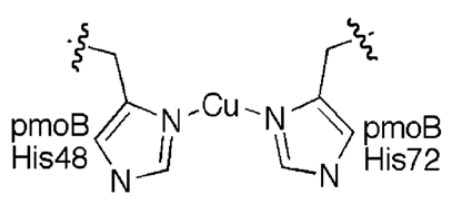

(B)

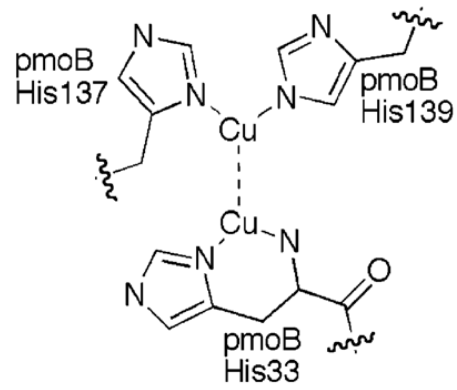

(C)

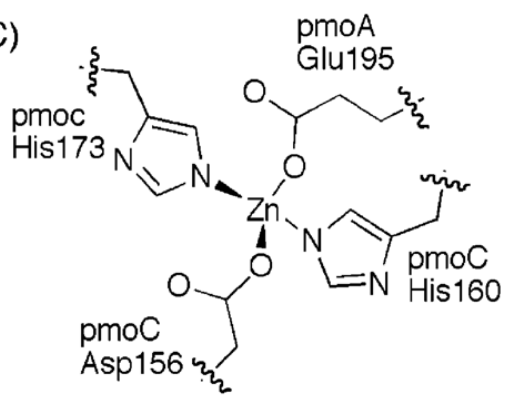

(D)

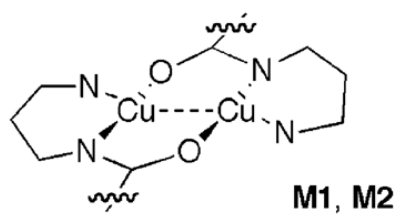

(E)

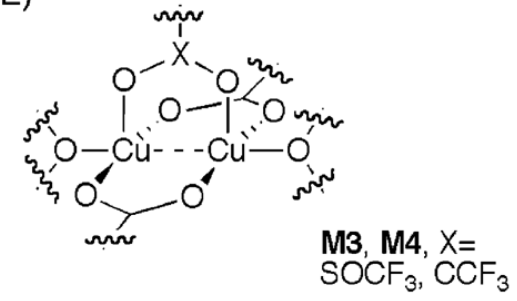

Figure 1.

Schematic diagrams of the pMMO metal centers $(\mathrm{A}-\mathrm{C})$ and $\mathrm{Cu}_{2}$ model compounds with short $\mathrm{Cu}-\mathrm{Cu}$ distances (D and $\mathrm{E}$ ). 


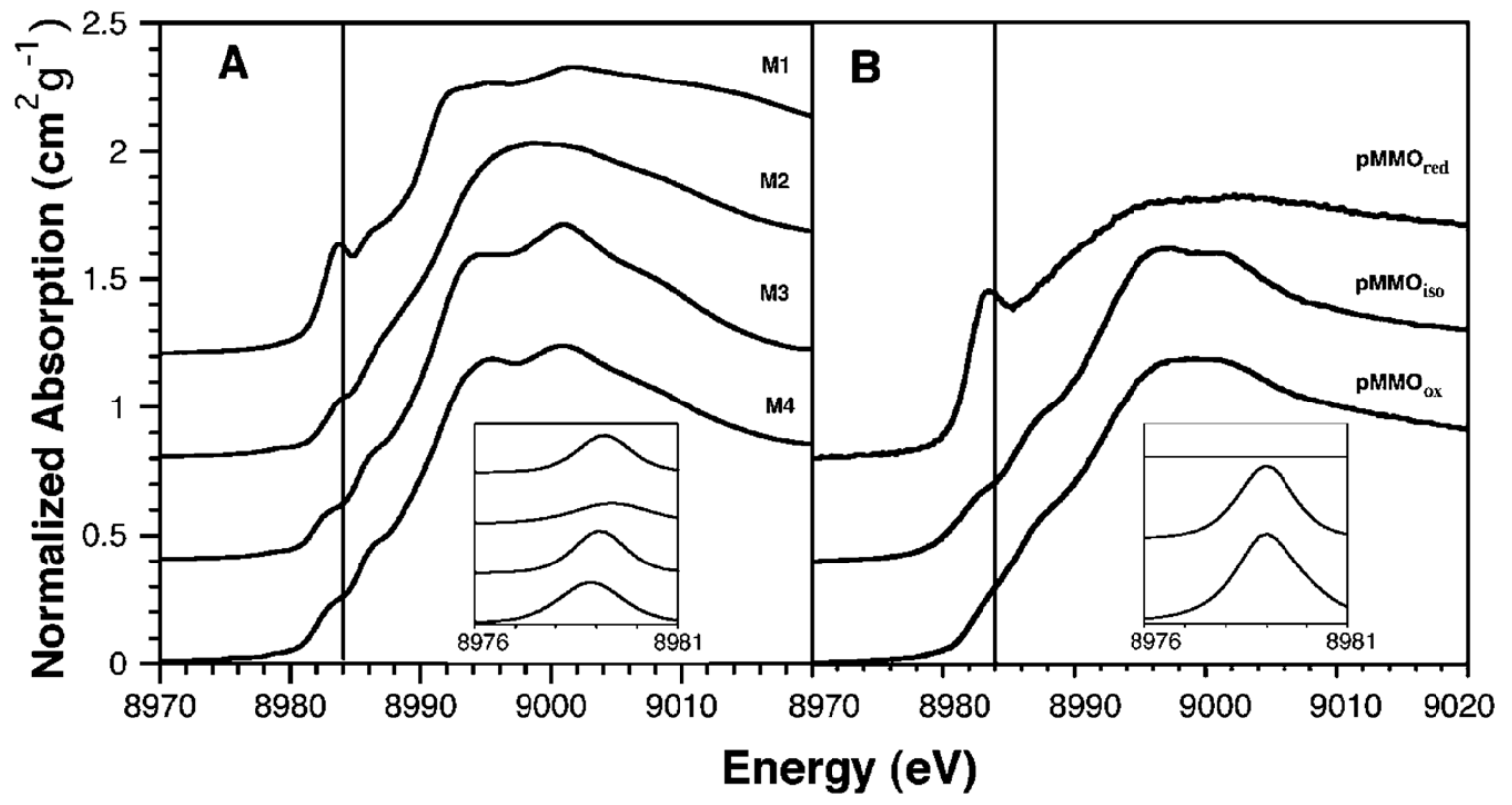

Figure 2.

$\mathrm{Cu}$ XANES spectra for mixed-valent model complexes (A) and pMMO samples (B). The spectra are offset vertically for clarity. The solid vertical line at $8984 \mathrm{eV}$ identifies spectral features corresponding to the $\mathrm{Cu}^{\mathrm{I}} 1 \mathrm{~s} \rightarrow 4 \mathrm{p}$ transition, and the insets show an expanded view of the $\mathrm{Cu}^{\mathrm{II}} 1 \mathrm{~s} \rightarrow 3 \mathrm{~d}$ transition. 


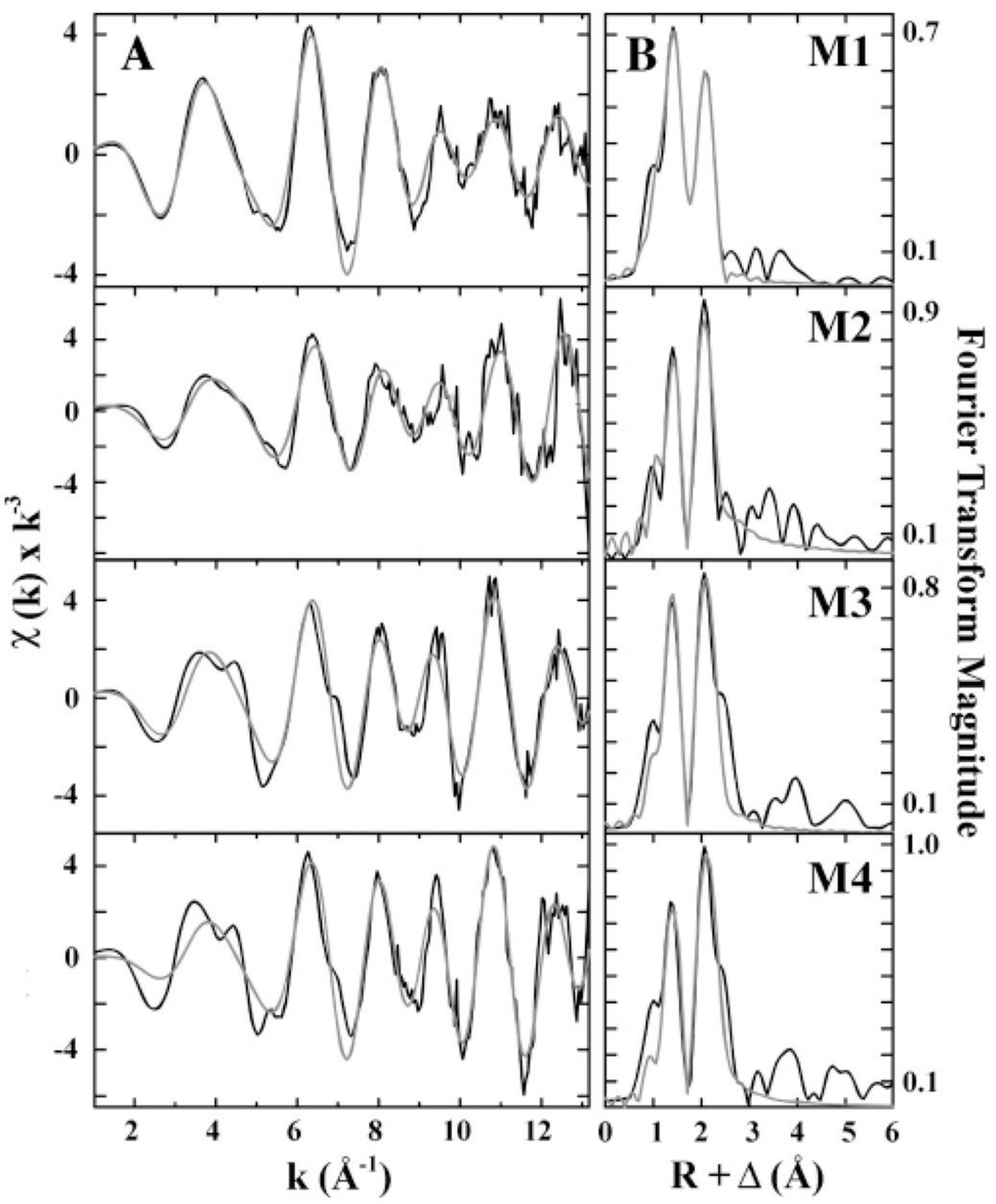

Figure 3.

Model complex $\mathrm{Cu}$ EXAFS fitting analysis. Panel A shows the raw unfiltered EXAFS data and fits, and panel B shows the Fourier transforms and simulated fits. Empirical data are in black, and simulated fits are in gray. Spectra were fit over a $k$ range of $1-13.1 \AA^{-1}$. 


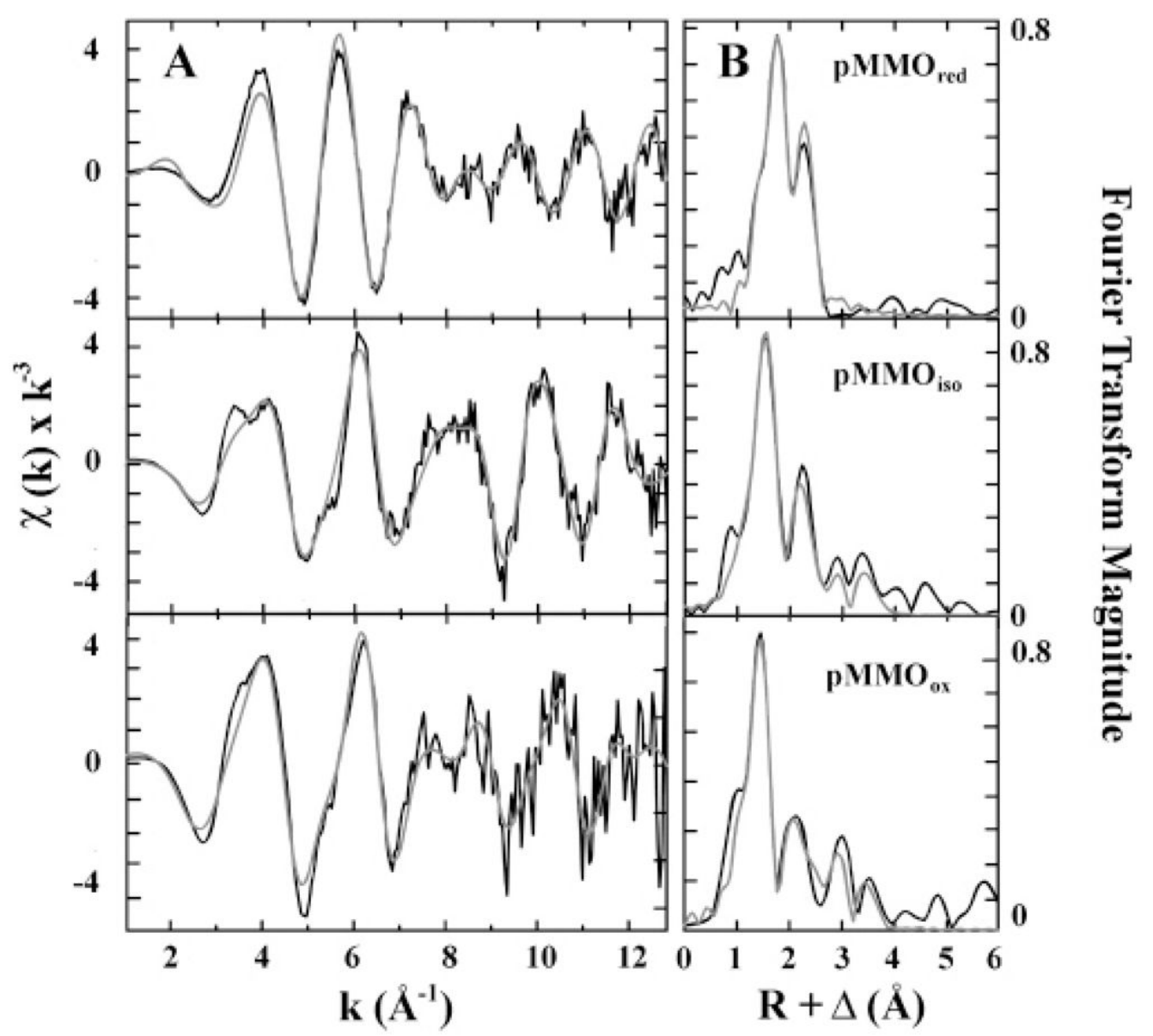

Figure 4.

pMMO Cu EXAFS fitting analysis. Panel A shows the raw unfiltered EXAFS data and fits for $\mathrm{pMMO}_{\text {red }}$ (top), $\mathrm{pMMO}_{\text {iso }}$ (middle), and $\mathrm{pMMO}_{\mathrm{ox}}$ (bottom). Panel B shows the Fourier transforms and simulated fits. Empirical data are in black, and simulated fits are in gray. Spectra were fit over a $k$ range of $1-12.85 \AA^{-1}$. 


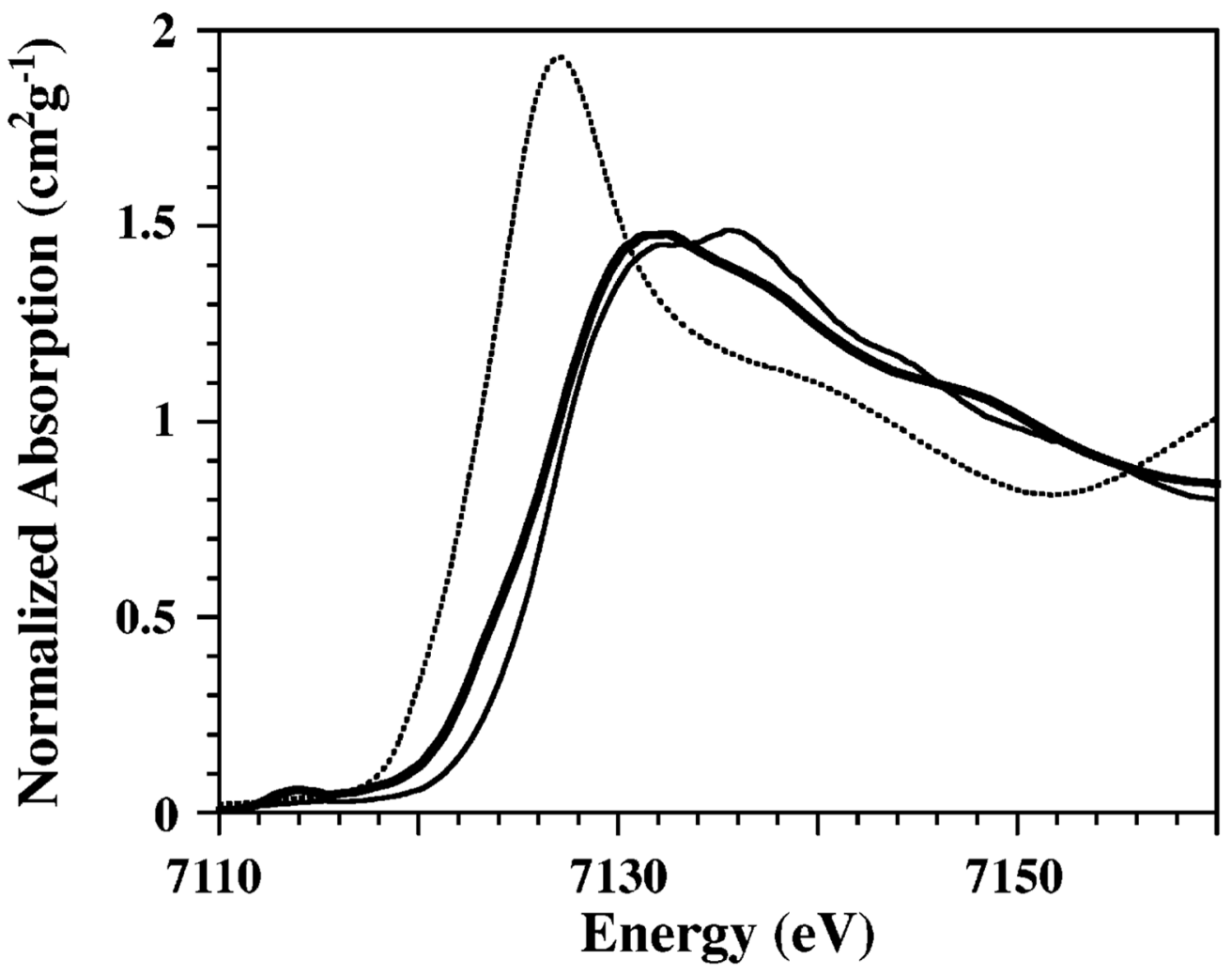

Figure 5.

Fe XANES spectra. Individual spectra correspond to ferrous ammonium sulfate (dashed line), ferric ammonium sulfate (solid line), and $\mathrm{pMMO}_{\text {iso }}$ (bold solid line). 


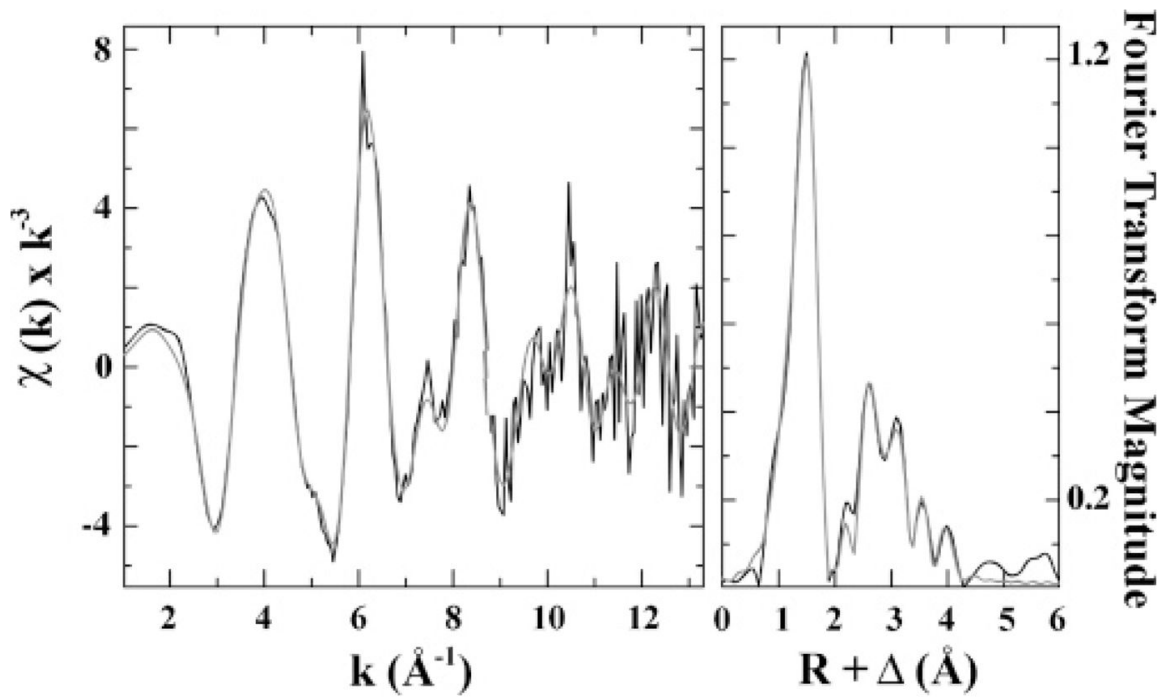

Figure 6.

pMMO Fe EXAFS fitting analysis. Empirical data are in black, and simulated fits are in gray. Spectra were fit over the $k$ range of $1-13.35 \AA^{-1}$. 


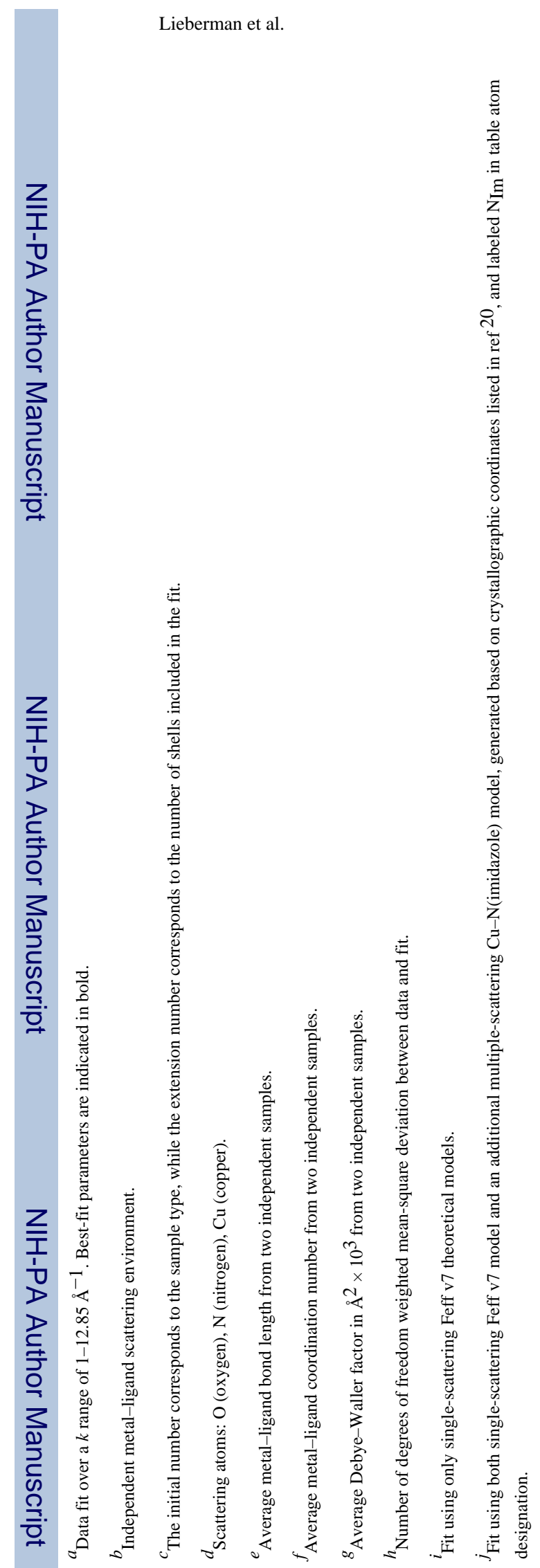

Inorg Chem. Author manuscript; available in PMC 2010 May 5. 
